\title{
The Social Psychology of Inclusion: How Diversity Framing Shapes Outcomes for Racial-Ethnic Minorities
}

Jamillah Bowman Williams

Georgetown University Law Center, jamillah.williams@law.georgetown.edu

This paper can be downloaded free of charge from:

https://scholarship.law.georgetown.edu/facpub/2427

https://ssrn.com/abstract $=4024504$

\section{Submitted for publication in peer-reviewed journal}

This open-access article is brought to you by the Georgetown Law Library. Posted with permission of the author. Follow this and additional works at: https://scholarship.law.georgetown.edu/facpub 


\section{The Social Psychology of Inclusion: How Diversity Framing Shapes Outcomes for Racial-Ethnic Minorities ${ }^{1}$}

Jamillah Bowman Williams, J.D., Ph.D.

Georgetown University

Research on the efficacy of organizational diversity efforts has yielded mixed results. It remains unclear when positive or negative outcomes should be expected, and why. This article fills a gap in the sociological literature by examining critical social psychological mechanisms. In Experiment 1, I found that common diversity messaging led to increased bias towards racial minorities. In Experiment 2, I examined how alternative framing may influence these outcomes. Findings revealed that the common "business case" emphasizing profit and performance gains made decision-makers less likely to select a Black job candidate than emphasizing civil rights law. I then examined social psychological mechanisms that make civil rights framing more effective. Discussing civil rights promoted the belief that striving for diversity is morally "the right thing to do," which mediated the promotion of a Black job candidate. Beyond theoretical contributions, findings can help organizational leaders better understand the effects of alternative diversity strategies.

Diversity training has become particularly popular among employers. It is estimated that companies invest $\$ 8$ billion annually on diversity training, with 67 percent of all U.S.

organizations and 74 percent of Fortune 500 companies utilizing such training (Hansen 2003;

Jayne and Dipboye 2004; Jones et al. 2013). For example, in 2018 Starbucks closed over 8,000

stores for anti-bias training. Likewise, following the murder of George Floyd and the ensuing mass protests and racial reckoning, scores of corporations, universities, hospitals, police departments, and other organizations responded by adopting diversity and anti-bias training.

Workplace diversity training can have a range of different goals, but typically aims to eliminate bias, promote inclusive decision making, and create unity and trust. Unlike traditional affirmative action programs that focus on groups protected by antidiscrimination law, diversity

\footnotetext{
1 Jamillah Bowman Williams, 600 New Jersey Avenue, NW, Washington, DC 20001-2075, jamillah.williams@law.georgetown.edu. An earlier version of this paper was presented at the opening plenary of the American Sociological Association annual meeting held in Philadelphia, PA in 2018. This project was funded by the National Science Foundation Dissertation Improvement Grant, a grant from the Stanford University Department of Sociology, a grant from the Stanford Institute for Research in the Social Sciences, and the American Bar Foundation/Law and Society Association/National Science Foundation Fellowship in Law and Inequality. I would like to acknowledge Cecilia Ridgeway and Shelly Correll for their mentorship, and the many other colleagues and reviewers who have provided thoughtful feedback at various stages of the project. I also thank my research team, including those who have provided valuable computer programming, research assistance, and editing. This project was truly a collective effort.
} 
training often emphasizes the value of a wide range of social differences. In addition to race, gender, and religion, trainings may also recognize diversity in geography, life experiences, and intellectual perspectives (Gratz v. Bollinger 2003; Mannix and Neale 2005; van Knippenberg and Schippers 2007; Mayorga-Gallo 2019). While diversity is a hot topic, it remains unclear whether the diversity management movement has been effective at improving intergroup relations and reducing racial inequality in organizations (Kalev et al 2006; Dobbin 2009).

Research on the efficacy of diversity efforts has yielded mixed results (Kalev et al. 2006). For example, some research has found efforts to be detrimental, some have found positive effects, and some have found no effect at all. In a study of over 700 establishments, Kalev et al. (2006) found that organizational training designed to promote diversity and reduce managerial bias led to a decline in the number of women and racial minorities in management over time. The authors conclude that this may result from employers adopting diversity efforts not to increase diversity, but rather to improve company morale or avoid legal liability. More specifically, they argue that training with a legal orientation may spoil the effects of such efforts by eliciting resistance (Dobbin and Kalev 2016; Kalev and Dobbin 2016). It is important to have organizational studies that capture the systemic nature of racial inequality, and to help question some of our assumptions about the efficacy of common diversity interventions.

While this landmark study provides important insights, the researchers note the limitations of using aggregate analysis with organizational level datasets. When we examine the effects of interventions, like diversity training, across hundreds of organizations, we learn very little about the micro level processes. Moreover, aggregating vastly different types of trainings in one single statistical model, without accounting for variations in framing, content, and delivery, further limits interpretation. This line of research must be extended to further explore how different types of training influence individual beliefs, emotions, behavior, and interpersonal relations in organizations (micro) and how these processes may be influenced by organizational context and macro societal factors (meso and macro) (Lawler et al. 1993; Reskin 2003; Kalev and Dobbin 2016). Research on the social psychological processes will help us learn more about which types of training may work, which are detrimental, and just as importantly why. While some qualitative research has begun to explore what organizational dynamics may influence outcomes, experimental studies are also a powerful tool to systematically investigate the 
mechanisms that mediate positive or negative effects.

This article fills a gap in the sociological literature by examining the critical social psychological mechanisms that may determine the impact of diversity training within organizations (Edelman et al. 2001; Reskin 2003; Kalev et al. 2006; Tinkler et al. 2007; Bond and Haynes 2014; Steele and Vandello 2019; Edelman et al. 2020). In Experiment 1, I use a laboratory experiment to investigate whether exposure to a common form of organizational diversity training generates positive diversity beliefs and inclusive decision making as intended. However, all diversity training is not created equally; so these findings tell only part of the story. For example, organizations use different framing to justify the importance of diversity, including but not limited to, rationales about improved performance brought by diversity and/or legal obligations. This difference in messaging may lead to different beliefs in those receiving the training and different outcomes for racial minorities.

In Experiment 2, a survey experiment, I build on results from Experiment 1 to examine whether some common types of diversity framing lead to more inclusive outcomes than others. For example, the primary rationale employers in the United States use to explain the importance of diversity focuses on meeting internal organizational goals such as profit, performance, and serving client needs, commonly known as the "business case" for diversity (Robinson and Dechant 1997; Edelman et al. 2001; Ely and Thomas 2001; Herring 2009; Phillips 2014). Alternatively, employers may focus on the need to comply with antidiscrimination law, making a legal case for inclusion (Edelman et al. 2001; Sturm 2001; Kidder et al. 2004; Dobbin 2009; Dobbin and Kalev 2013). This alternative framing may influence the extent to which a particular diversity training yields positive outcomes, such as equitable management decisions and reduced bias.

Further, I investigate why some framing of diversity training may be more effective than others. I do this by examining the social psychological mechanisms that may mediate inclusive managerial decisions such as employee evaluations and promotions. For example, mechanisms such as positive diversity beliefs may facilitate workplace decision-making more inclusive of racial minorities (see Figure 1). 


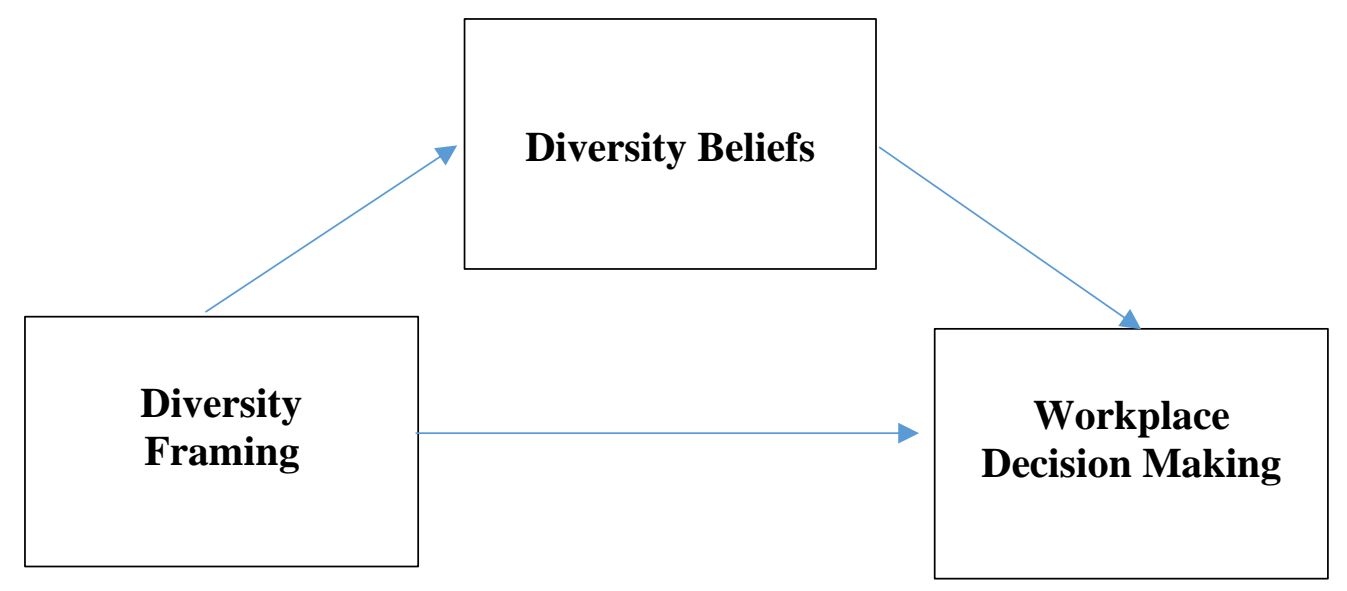

Figure 1. The Effect of Diversity Framework Mediated by Diversity Beliefs STRATEGIC FRAMING OF DIVERSITY: BUSINESS CASE VS. CIVIL RIGHTS

Organizations offer a range of frames to validate diversity and inclusion. Frames, defined as "schemata[s] of interpretation," are designed to organize and guide both individual and collective action, including decision-making (Goffman 1974:21; Snow et al. 1986). Research in behavioral economics has demonstrated the impact of the various social psychological processes on decision-making, including framing effects. Framing effects is a term describing how the way one chooses to present information can affect the decisions other individuals will make based on that information (Camerer and Loewenstein 2003). For example, the way an organization chooses to frame their diversity values and objectives may promote different levels of buy-in to related policies, practices, and values.

An organization's strategic rationale for diversity, and how employees perceive this framing, may influence the extent to which the ultimate goals are either resisted, internalized, or ignored. Two common rationales for diversity include: (1) business case (profit, performance, diverse customers); and (2) legal (civil rights law, compliance). The most frequently cited reason in managerial literature in support of organizational diversity is how it enhances profit, with nearly half of practitioners mentioning this as a fundamental reason to strive for diversity (Edelman et al. 2001). Of the articles referring to workplace diversity, nearly 50 percent referred to its value for organizational profit, while only 19 percent referred to law as a reason for supporting diversity, and only 30 percent mentioned fairness (Edelman et al. 2001).

In this article, I focus primarily on comparing business and legal framing of diversity 
messaging. I start with these two rationales because organizations often have separate departments that frame diversity goals in these two ways. Legal/compliance/affirmative action offices frame goals and training in terms of antidiscrimination law and civil rights, whereas Diversity and Inclusion offices tend to frame goals and training in terms of the business case and the improved organizational outcomes. The business case focuses on using inclusion to reap rewards, while legal compliance typically focuses on using inclusion to avoid punishments.

\section{The Business Case: Profit \& Productivity}

A business case rationale emphasizes the bottom line, with a goal of convincing organizational actors that diversity will benefit them, their group, or their organization in some way. For example, studies suggest that diverse organizations will experience positive performance outcomes because diverse perspectives and viewpoints will help them reach group goals (Ely and Thomas 2001; Page 2007; Phillips, Liljenquist, and Neale 2009) and lead to higher profits (Herring 2009; McKinsey 2020). A large body of interdisciplinary literature supports the business case for diversity by showing a variety of ways that diversity improves performance while pointing out that homogeneity, which can lead to "group think" and other negative outcomes, undermines it (Ely and Thomas 2001; Phillips et al. 2006; Page 2007; Herring 2009; Loyd et al. 2013).

Seemingly a win for everyone, business case framing has great rational appeal - everyone likes success and profits. This reasoning makes the business case for diversity a popular framing technique, not only for workplace training, but also for organizational vision statements, corporate advertising, and pitches for policy change. However, we lack scientific study of whether this framing is actually persuasive and effective at promoting more inclusive behaviors and better outcomes for racial minorities. While the business case may be intended to increase buy-in to inclusion efforts and reduce resistance by finding common ground, the actual effect of this strategy on beliefs and behavior remains unclear. For instance, some who are currently advantaged (e.g. White males) may fear they will lose from diversity efforts, and others may be skeptical about the asserted benefits, making them less likely to accept the business case for diversity (Norton and Sommers 2011).

\section{Legal Compliance}

Most employers must adhere to federal, state, and local equal opportunity laws, and many 
invest additional resources that go beyond what is required by law. The antidiscrimination mandate with the greatest effect on organizations is Title VII of the Civil Rights Act of 1964, which prohibits discrimination on the basis of race, color, religion, sex, or national origin. An outcome of the civil rights movement, this law represented a major turning point in employment relations, opening organizational governance to public scrutiny and legitimating employees' demands for fair treatment. With a legal compliance rationale, the primary goal of pursuing diversity and inclusion is to keep pace with antidiscrimination requirements and to avoid punishment, including costly litigation.

In contrast to the business case, some research suggests that diversity efforts are especially likely to result in resistance if employees perceive them to have an externally driven legal rationale that reflects no internally motivated organizational value (Krieger 2000; Edelman et al. 2001; Kidder et al. 2004; Kalev et al. 2006; Li et al. 2007; Bartlett 2009; Kalev and Dobbin 2016). However, it remains unclear whether a legal framing focused on civil rights law makes training less effective than framing around business outcomes, and if so, why.

Further, research on the positive normative influence of law also leaves the possibility that framing around civil rights law may fare well when promoting inclusion goals (Suchman 1997; Albiston et al. 2012; Albiston and O’Connor 2016). Based on this theory, the law has a

symbolic effect that engenders shared values about what is right and wrong. In doing so, the law assists in creating an implied social consensus around inclusion goals, which in turn can change individuals' normative evaluations of the goals as well (Albiston et al. 2012; Albiston and O’Connor 2016). This normative influence is just one mechanism through which organizations can utilize framing effects to promote a desired outcome.

PREDICTING THE EFFECTIVENESS OF DIVERSITY TRAINING: SOCIAL PSYCHOLOGICAL MECHANISMS

To investigate why some strategic framing of diversity may be more effective than others, we must examine the social psychological mechanisms involved. While diversity training is designed to embrace difference, reduce inequality, and promote compliance, it may also result in resistance. Social psychologists and organizational researchers have begun to explore resistance and backlash to diversity and EEO policies (Bobo, Kluegel, and Smith 1997; Plant and Devine 2001; Holladay et al. 2003; Kidder et al. 2004; Thomas and Plaut 2008). Certain diversity messaging or initiatives are particularly at risk of causing Whites to resist 
inclusion efforts. For example, some may deny inequality exists (Kaiser et al. 2013; BonillaSilva 2021), assert that they are the true victims of organizational bias (Norton and Sommers 2011), or take action to restore the status quo by exhibiting increased bias (Dover, Major, and Kaiser 2016).

Certain diversity framing, particularly around civil rights, may generate resistance because if it triggers a prevalent colorblind ideology. Colorblind ideology is a growing trend among Americans, rooted in the belief that race should not and does not matter in interactions and everyday life (Neville et al. 2013; Bonilla-Silva 2021). Such an ideology maintains that inequalities are driven by factors such as social class, individual motivation values, and meritocracy rather than race or ethnicity. This belief that racism is unimportant/insignificant is bolstered by the fact that racial discrimination is formally outlawed (Williams and Cox 2020). Thus, legal framing may make people think discrimination solved and a thing of the past, which could lead them to reject legal framing. Colorblind ideology could also lead people to reject the business case framework. The business case suggests that organizations should capitalize on race/ethnic differences to reach optimal levels of success. If individuals claim to not see race, or that race is irrelevant, then they might see this goal of acknowledging, valuing, and capitalizing on difference as unnecessary and possibly even offensive.

Strategic framing of diversity - as an issue related to business outcomes or civil rights law - may also influence one's diversity beliefs. This includes their perceptions about whether diversity is an important goal, diversity efforts have gone too far, or whether diversity efforts are "the right thing to do" morally (Meuse and Hostager 2001; Williams and Cox 2020). Diversity ideology, as defined by David G. Embrick (2011) explains how one's beliefs about diversity may mediate behavior. It is based on four tenets: diversity as acceptance, diversity as intent, diversity as commodity, and diversity as liability (Mayorga-Gallo 2019). These tenets work to increase the appearance of symbolic support for diversity, while simultaneously minimizing individual responsibility for rectifying inequalities or generating structural change. The commodity tenet, for example, allows individuals to acknowledge the economic or performance benefit diversity can bring to their organization, while failing to take individual actions that would remedy the structural disadvantages based on race and/or ethnicity (Williams and Cox 2020). 


\section{RESEARCH QUESTIONS}

Two related experimental studies explore three primary research questions:

(1) How does exposure to a diversity training video influence outcomes for a Black teammate in a group decision-making task?

(2) Does framing training around civil rights law produce different beliefs about diversity and decisions regarding a Black job candidate, compared to framing around the business case for diversity?

and

(3) If organizational framing does influence outcomes, what are the social psychological mechanisms at play?

\section{EXPERIMENTAL DESIGN}

I use experimental methods to systematically examine the pivotal social psychological mechanisms that influence the success or failure of strategic diversity framing. Experiments are designed to create theoretically relevant aspects of social situations under controlled conditions (Zelditch 1969). In real organizations, the environment is very complex and there are infinite confounding factors that interfere with our ability to examine a particular part of a social psychological theory. With an experiment, we can know with greater certainty that the manipulated variable causes the effect rather than other extraneous variables. Building on these methodological strengths, the relative effects of alternative diversity framing can be studied in an organization created artificially in the laboratory or in a survey experiment. Experiment 1 investigates how exposure to organizational diversity training influences diversity beliefs and decision making. Experiment 2 builds on these findings to explore the differential effects of legal and business case framing for diversity, and the mechanisms that may lead to improved outcomes.

\section{EXPERIMENT 1}

Sample. This randomized experiment provides an initial test of how diversity training may influence workplace decision making. Sixty-nine White undergraduate students participated in the study; six who did not complete the study were excluded, resulting in a final sample of $63 .{ }^{1}$ Fifty-seven percent of the participants were female, and they ranged from 18-23 
years of age.

Experimental manipulation. Participants were randomly assigned to one of three conditions. Each condition presented a different video resembling an organizational training. In the Diversity condition, the footage included graphics of corporate offices, organizational charts, and racially diverse students and professionals, many working in teams. The images were downloaded from the internet using Google images and the narration was recorded by a professional voice-over specialist (see Figure 2). During the video, the narrator described the importance of diversity and the benefits it yields in organizations. This echoes the "business case" for diversity, which is the most common framing offered by managers and consultants (Edelman et al. 2001; Esen 2005; Herring 2009). More specifically, the video stated that research has found diverse groups to be most effective in a range of tasks, leading to greater success in the workplace and educational settings.

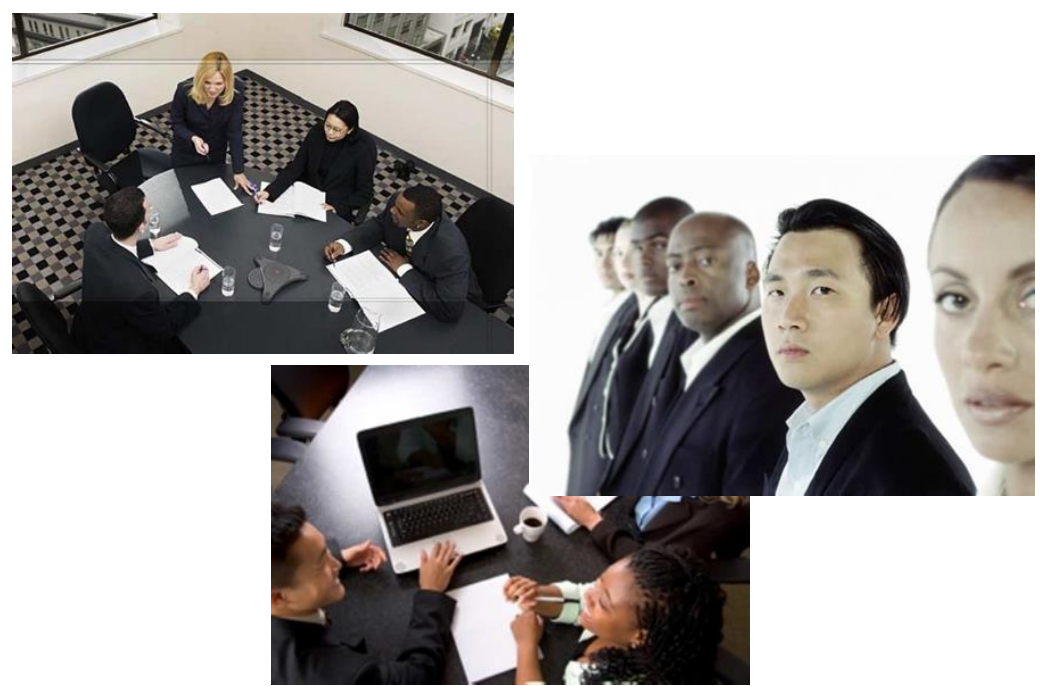

Figure 2. Sample Diversity Video Imagery

In the Mainstream control condition, the video did not project a value of diversity. The images included a more traditional and mainstream workforce with mostly older White male professionals, a few White females, and a token number of racial minorities. This condition was consistent with the lack of racial diversity observed in many high-status professions such as technology, finance, and law. In the mainstream video, the narrator discussed organizational performance more broadly, with no mention of diversity (see Figure 3). 

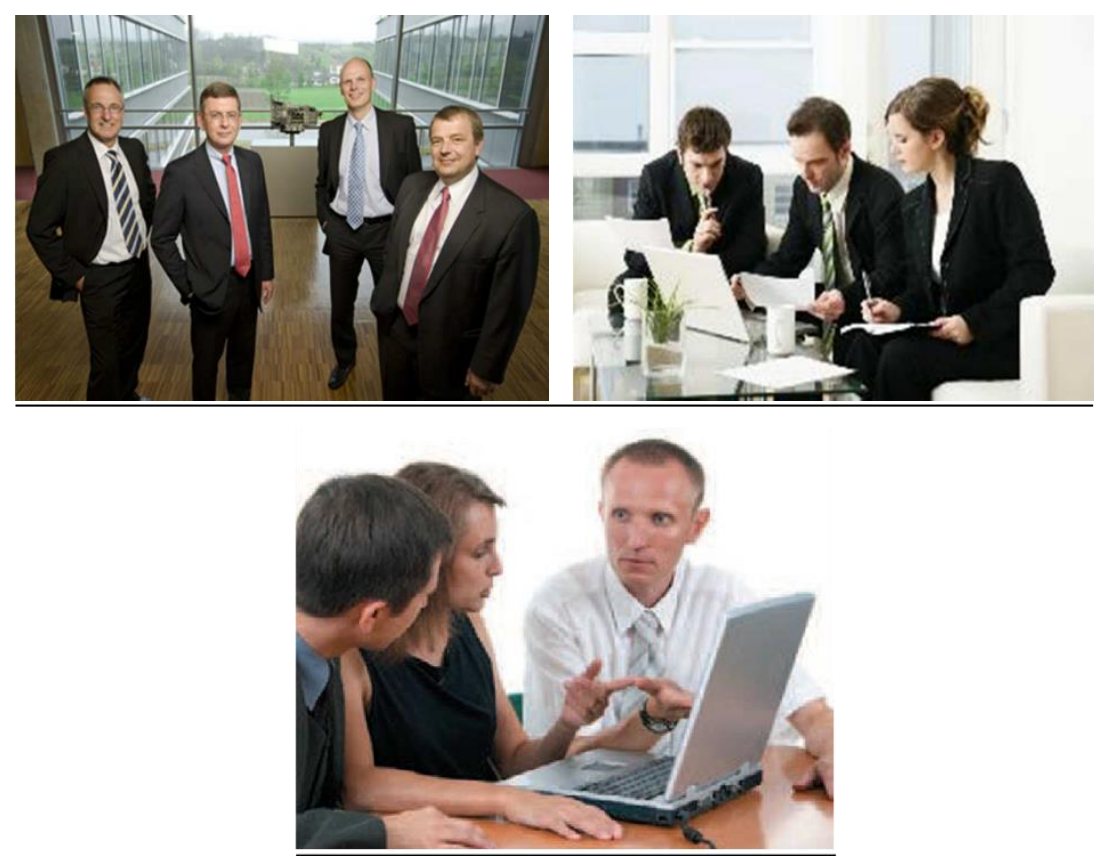

Figure 3. Sample Mainstream Video Imagery

The Neutral control condition featured neutral organizational logos and imagery, such as office boardrooms and organizational charts. It showed no people and thus provided no cues about race or gender composition or other values regarding diversity. Like the mainstream video, the narrator discussed organizational performance more broadly, but made no mention of diversity. This condition was designed to capture baseline outcomes in a neutral environment (see Figure 4).
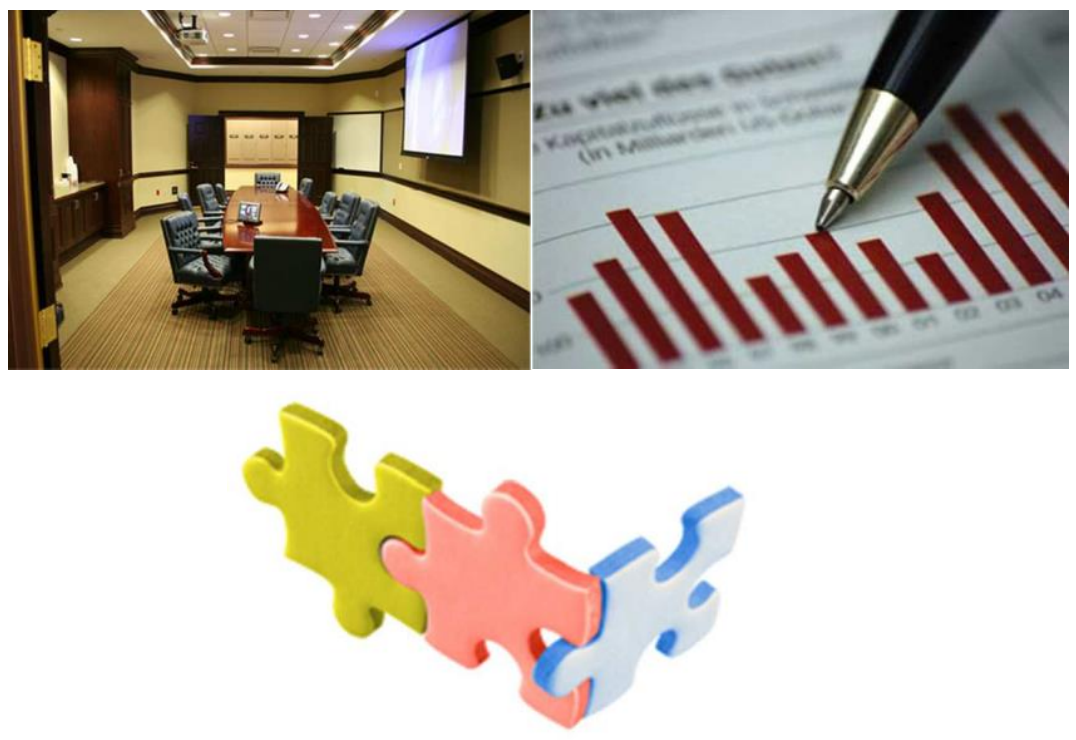

Figure 4. Sample Neutral Video Imagery 
Procedure. Participants were told the study was being conducted by the Center for Organizational Performance (a fictitious organization). In each condition, using an interactive computer system, participants joined a team with two fictitious pre-programmed teammates one White and one Black. They were led to believe that the teammates were real participants also present at the study location. Participants were told that the team would be working together to resolve a number of organizational scenarios. The participant was asked to take a picture and they were provided with pictures of their teammates. Participants were matched to teammates of the same gender. Based on pretests, the two teammates, per the photos, were equivalent in attractiveness, age, and other characteristics.

Before being introduced to teammates via computer, participants watched one of the three video presentations on screen. After viewing the video, participants were introduced to the two teammates via photographs and short descriptions. They were told that they would complete three projects with their team, each with increasing difficulty and interaction. The White participant was then informed that he/she was randomly selected as group leader for the first task. The group task involved 20 multiple choice questions regarding the best course of action to take when faced with a management problem. All multiple choice questions were selected from civil service exams and, unbeknownst to participants, the correct answer was removed from the answer choices for each question (Lucas 2003). With the correct answer removed, questions were ambiguous and difficult with no clear correct response. The responses were randomly assigned to each teammate, with a pre-programmed number of agreements and disagreements. This instrument has been used successfully in past research (Lucas 2003).

The interactive computer program collected data, recorded patterns in the decisionmaking process, and administered survey questions throughout the group task. Participants selected their individual responses to each scenario, then after a brief delay, were able to view the responses of their teammates by clicking on their names and pictures. For each question, after reviewing their teammates' responses, the White participant, in the role of leader, was responsible for selecting the final answer for the group. After the final question, the participant was asked to evaluate each group member's performance. A report then informed the participant that he/she answered fewer questions correctly than the other two teammates and that the group performed below the average of most teams. The participant was then given the choice of appointing one of his/her teammates as group leader or retaining that role for the second task. 
The final segment asked participants to answer eight questions for a separate research study. This final survey measured diversity beliefs and contemporary racial attitudes.

Measures. To measure behavior that simulates workplace decision making, I asked the participant to make a leadership decision that was tied to organizational rewards. Following the group decision-making task, the participant was asked to select a member of the team as leader for the subsequent task. I instructed them that the entire team would be rewarded for high group performance and the leader would receive a bonus reward. The responses were coded into a dichotomous variable, $1=$ Black teammate selected as group leader and $0=$ Black teammate not selected as group leader. ${ }^{2}$ Using a t-test, the percentage of participants who selected the Black teammate as group leader in the Diversity condition was compared to the percentage of participants who selected the minority teammate in the Mainstream and Neutral control conditions.

I measured the participant's diversity beliefs about the performance value of diversity by asking at the end of the study whether they agree that, "Diverse teams perform better than racially homogeneous teams." This variable was measured on a five-point Likert scale, from "Strongly Disagree" to "Strongly Agree," and average responses were compared across the three conditions using a t-test.

I used eight questions from the Symbolic Racism Scale 2000 to measure whether the diversity video influenced participants' racial attitudes (Sears and Henry 2005) (see Appendix A). These beliefs are a blend of negative feelings toward Black people and conservative values. For example, one question asks, "How much discrimination against blacks do you feel there is today limiting their opportunity to get ahead?" measured on a four-point Likert scale from $1=$ "A lot" to 4 = "None at all."

Results. Experiment 1 revealed that the White participants were less favorable to the Black teammate in the Diversity video condition, compared to those in the Mainstream and Neutral control conditions (see Table 1). A statistically significant result indicates that the mean differs from that in the Diversity condition. White participants who viewed the Diversity video were less likely to select the Black teammate as group leader than participants in the Mainstream and Neutral conditions. Only 36 percent of participants in the Diversity condition selected the Black teammate, while 67 percent of participants in the Mainstream condition selected the 
minority, $\mathrm{t}(41)=2.04, \mathrm{p}=0.048$. In the Neutral condition, 50 percent selected the minority, $\mathrm{t}(40)=0.88$, n.s.

On average, White participants randomly assigned to the Diversity video condition expressed more negative beliefs about diversity than participants randomly assigned to the Mainstream and Neutral conditions. Participants were more likely to agree with the statement "Racially diverse teams perform better than racially homogeneous teams" in both the Mainstream condition $(M=2.95), \mathrm{t}(41)=2.23, \mathrm{p}=0.032$ and the Neutral condition $(M=3.00)$, $\mathrm{t}(40)=2.13, \mathrm{p}=0.039$ when compared to the Diversity condition $(M=2.31)$. The only participants who were exposed to a narrative about the value of diversity were those who viewed the Diversity video which covered research findings demonstrating that diversity leads to benefits in teams and organizations. Yet, participants who received this message were less likely to agree that diversity is beneficial to team performance than participants in the control conditions. This suggests that participants rejected these common notions around the benefits of diversity and were not convinced that racial diversity will benefit them, their group, or their organization in some way.

Participants' racial attitudes, measured by the Symbolic Racism scale, did not statistically vary across conditions. Participants were equally as likely to agree with statements such as "More good jobs for Blacks means fewer good jobs for Whites," and that "Blacks are getting more than they deserve" in all conditions. This finding supports the social psychological theory that racial attitudes are now more liberal, with explicit racism less frequently observed. Further, resistance to diversity training may operate through subtle and possibly unconscious processes that are not directly related to explicit racial attitudes.

Table 1. Mean Leadership Decision, Diversity Beliefs, and Racial Attitudes by Diversity Video: Diversity vs. Mainstream and Diversity vs. Neutral

\begin{tabular}{lccc}
\hline & Diversity & Mainstream & Neutral \\
\hline $\begin{array}{l}\text { Leadership Decision } \\
\begin{array}{l}\text { Ps that Selected Black Leader (0-100\%) } \\
\text { Diversity Beliefs }\end{array}\end{array}$ & 36.36 & $66.67^{*}$ & 50.00 \\
$\begin{array}{l}\text { Diverse Teams Perform Better than Homogeneous Teams } \\
\text { Contemporary Racial Attitudes }\end{array}$ & 2.31 & $2.95^{* *}$ & $3.00^{* *}$ \\
$\quad$ Symbolic Racism Score & 22.05 & 21.24 & 21.80 \\
\hline$* \mathrm{p}<.05 * * \mathrm{p}<.01$ & & &
\end{tabular}


Summary. In Experiment 1, race was not relevant to the group decision-making task. In fact, task-specific evidence indicated that both the Black and White teammates were high performers. Yet White participants treated the Black teammate more negatively after being exposed to messaging about the value of diversity. This result raises serious questions about diversity trainings that emphasize performance benefits as a way of persuading employees to embrace diversity and engage in more inclusive behavior. In short, this strategy may backfire. Leadership positions bestow status and organizational rewards. If Black employees and other racial minorities are systematically disadvantaged in the leadership selection process, that outcome will continue to reinforce inequality in the workplace and other organizational contexts. This type of resistance to diversity training may lead to no improvement in minority representation over time, or even decrease representation for some groups (Kalev et al. 2006; Dobbin and Kalev 2016).

\section{EXPERIMENT 2}

In Experiment 2, I build on findings from Experiment 1 by investigating whether different framing about the rationale for diversity and inclusion leads to different outcomes. In Experiment 1, the narrative in the Diversity video emphasized that diversity is valued because of its benefits to innovation, productivity, and team performance, the common business case for diversity. The business case narrative paired with imagery of diverse teams led to worse outcomes for the Black teammate.

Findings from Experiment 1 raised many important questions. For example, do all diversity trainings lead to negative behaviors toward racial minorities or may certain framing lead to greater inclusion? This study tests competing predictions based on prior research that: (1) a legal rationale will be less effective than the business case due to greater resistance; and (2) the legal rationale will be more effective because of its normative influence (Sturm 2001; Albiston et al. 2012; Kalev and Dobbin 2016). In addition to examining whether framing can influence outcomes, Experiment 2 further examines mechanisms to explore why some framing may be more successful than others.

Sample. Two hundred thirty-three alumni and parents of students at a West Coast university participated in the study. Thirteen who did not view the video manipulation were dropped, leaving a sample of 220. Respondents ranged from 22 to 94 years of age, with an 
average age of 52. The sample was 70 percent White, 20 percent nonwhite (Black, Asian, Latinx, Native American), and 10 percent Other or not reported. Participants resided in 33 states and held a wide range of employment experiences. Eighty-two percent had managerial experience. This survey sample is broader than an undergraduate sample for increased generalizability. ${ }^{3}$

Experimental manipulation. The diversity framing was manipulated by a two-minute online video which each participant viewed at the beginning of the experiment. The video exposed participants to one of four conditions including: (1) Business Case; (2) Civil Rights Law; (3) Business Case and Civil Rights Law; and (4) No Rationale. All four videos discussed the importance of diversity and inclusion, but the narrator framed diversity and inclusion with a different rationale in each condition. The imagery in the videos illustrated diverse individuals in a range of business and team settings and was identical across conditions.

In the Business Case video, the narrator suggested that diversity and inclusion are important because corporations and other organizations benefit from a diverse workforce. The script asserted that diversity along race, gender, national origin, and age, among other factors, increases innovation and productivity, is a profitable resource, and is necessary in a competitive market. The video also stated that people from these different groups bring different perspectives which are valuable in decision making and problem solving and result in a wider range of strategies to attack problems and address diverse customer needs. This rationale was not presented as a mandate. Instead, it was depicted as internally driven, desired by organizations, and key to enhancing the success of the group and organization. The message in this video was very similar to that presented in the Diversity condition video in Experiment 1.

In the Civil Rights Law video, the narrator stated that diversity and inclusion are important in organizations because of legal requirements such as federal antidiscrimination law. The video suggested that diversity should be a priority to comply with the law and avoid litigation, mentioning Title VII of the 1964 Civil Rights Act which prohibits employers from discriminating on the basis of race, color, sex, national origin, and religion. The video also stated that the law has certain requirements and, in order to maintain compliance, companies must seek to include people from these different protected groups.

The combined Business Case and Civil Rights Law video emphasized the legal requirements, yet also described the organizational benefits of diversity. The video highlighted 
the problems of discrimination and exclusion from a legal standpoint, in terms of maintaining compliance and avoiding litigation, and from a business standpoint because they limit the company's ability to profit in a global marketplace with diverse customer and client needs. A real-world example of this is a company that responds to a discrimination lawsuit by strengthening diversity programs to avoid future lawsuits while simultaneously promulgating the performance benefits of such diversity.

Lastly, in the No Rationale condition, the video expressed the value of diversity, but did not state any specific rationale. This condition served as a control to compare with the other three conditions.

Procedure. After viewing the video, participants completed a 15-minute survey which asked them to: (1) review an organizational scenario involving a promotion that ambiguously involved issues of social inequality; (2) answer questions regarding their reactions and a suggested decision regarding the promotion; and then (3) respond to survey items regarding diversity beliefs and colorblind racial attitudes.

Measures. The promotion decision involved a scenario where a White candidate was promoted over a racial minority candidate (Green 2003; Williams and Cox 2020). Race was primed using a stereotypically Black name "Darnell," a stereotypically White name "John," and by Darnell's expressing concern at the lack of racial minorities receiving promotions, and subsequently requesting his own review of his own lack of promotion on that basis (Levitt and Dubner 2005; Williams and Cox 2020). The scenario described an employment setting where subtle structural barriers may disadvantage racial minorities (see Appendix B). The survey item read: "Only one person in this division can be promoted. At this point, based on your expertise and opinion, what preliminary recommendation do you wish to submit to the committee?" The response options were: "Definitely Promote John”; “Definitely Promote Darnell”; "Probably Promote John"; or "Probably Promote Darnell."

To measure diversity beliefs, the survey asked participants several questions regarding whether diversity should be an important goal in organizations. The first question asked generally, "Do you believe it is important to strive for diversity in the workplace?" This general value of diversity was measured on a scale from 0 to 100 with $0=$ "Not At All Important" and $100=$ "Extremely Important." Participants were then asked more specifically about different 
rationales for diversity. "To what extent do you believe the following factors are important reasons to strive for diversity in the workplace?" The survey listed a number of specific rationales, such as, "It introduces a broader range of viewpoints for workplace decisions"; "It prevents discrimination lawsuits"; and "It is the right thing to do morally." Responses were recorded on a seven point Likert scale from $1=$ "Not at All Important" to 7 = "Extremely Important."

The Color Blind Racial Attitudes Scale (CoBRAS) was used to measure colorblind attitudes (Neville et al. 2000) (see Appendix C). In general, a high score on this multi-factor scale indicates that the respondent denies the existence of racism and believes that race does not and should not matter (Bonilla-Silva 2021). Participants were asked to report whether they agreed or disagreed with a number of statements. There are three components to the scale including Racial Privilege, Institutional Discrimination, and Blatant Racial Issues. Items were measured on a five point Likert scale from "Strongly Disagree" to "Strongly Agree." Some items were reverse coded as appropriate. Scores on the CoBRA scale were compared across conditions using t-test analyses. The survey also asked participants to provide information on gender, race, age, occupation, managerial experience, and geographic location.

Results. Table 2 shows mean diversity beliefs and colorblind racial attitudes. The conditions are compared using two-sample t-tests. The primary comparison of interest is between the Business and Legal conditions, both common framing in organizations and hotly debated. The other conditions offer useful insights as well. In general, findings reveal that framing diversity around civil rights law evokes a more positive response than does a business case for diversity. This does not support the common expectation which holds that the business case for diversity grounded in performance benefits is perceived to be the most legitimate and results in more inclusive beliefs and behavior than exposure to antidiscrimination law.

When examining diversity beliefs, participants viewing the Business Case video were no more likely to support business rationales around the benefits for diversity than participants in the Civil Rights Law condition. For example, participants exposed to Civil Rights Law were just as likely to respond that striving for diversity leads to innovation, as participants in the Business Case condition $\mathrm{t}(107)=0.246, \mathrm{p}=0.806$ and marginally more likely to believe that striving for diversity leads to success in the global market $\mathrm{t}(107)=1.677, \mathrm{p}=0.096$. Participants in the Civil 
Rights Law condition were also more likely to agree that striving for diversity is "the right thing to do morally" $\mathrm{t}(107)=2.64, \mathrm{p}=0.009$ and "provides a fair chance to the underrepresented," $\mathrm{t}=$ 2.699, $\mathrm{p}=0.008$, relative to participants in the Business Case condition.

Lastly, based on the Colorblind Racial Attitudes Scale, participants in the Civil Rights Law condition were more likely to acknowledge inequality and bias than participants in the Business Case condition, $\mathrm{t}(100)=-2.52, \mathrm{p}=0.013$. Higher scores on the CoBRAS indicate more negative racial attitudes. The strongest differences emerged in the scale component measuring whether one acknowledges institutional discrimination, where participants exposed to civil rights law exhibited more awareness than those exposed to the business case $\mathrm{t}(105)=-2.72, \mathrm{p}=0.008$. Those exposed to civil rights framing were less likely to believe that: racial minorities have advantages based on their skin, that affirmative action discriminates against Whites, and that it is important for us to think of ourselves as American and not Mexican American, Black, or Italian American.

While combining the Business Case with the Civil Rights rationale yielded more positive effects than the Business Case alone, neither were as effective as the Civil Rights Law rationale which discussed antidiscrimination law with no reference to profit, performance, or competitive advantage.

Table 2. Mean Diversity Beliefs and Racial Attitudes by Diversity Rationale

\begin{tabular}{lccccc}
\hline Condition & $\begin{array}{c}\text { Business } \\
\text { Case }\end{array}$ & $\begin{array}{c}\text { Bus+ } \\
\text { Civ. Rights }\end{array}$ & $\begin{array}{c}\text { Civil Rights No Rationale } \\
\text { Law }\end{array}$ & \\
\hline Diversity Beliefs & $\mathrm{n}=54$ & $\mathrm{n}=54$ & $\mathrm{n}=55$ & $\mathrm{n}=57$ \\
\hline \multicolumn{1}{c}{ Important to Strive for Diversity } & 68.00 & 70.25 & 75.15 & 71.14 \\
$\quad$ Leads to Innovation & 5.80 & 5.63 & 5.85 & 5.68 \\
Success in Global Market & 5.65 & 5.91 & 6.04 & 5.95 \\
$\quad$ The Right Thing to Do Morally & $4.70^{\mathrm{bc}}$ & 5.07 & 5.47 & 5.36 \\
$\quad$ Provides Fair Chance to Underrepresented & $5.00^{\mathrm{bc}}$ & 5.09 & $5.62^{\mathrm{de}}$ & 5.29 \\
\hline Colorblind Racial Attitudes Scale (CoBRA) & $52.78^{\mathrm{b}}$ & 51.68 & 50.81 & 51.35 \\
CoBRA - Institutional Discrimination & $16.90^{\mathrm{b}}$ & 16.30 & 15.29 & 16.13 \\
\hline
\end{tabular}

\footnotetext{
${ }^{a}$ Business vs Business + Civil Rights $(\mathrm{p}<.05)$

${ }^{\mathrm{b}}$ Business vs Civil Rights ( $\left.\mathrm{p}<.05\right)$

${ }^{\mathrm{c}}$ Business vs No Rationale ( $\left.\mathrm{p}<.05\right)$

$\left.{ }^{\mathrm{d} C i v i l ~ R i g h t s ~ v s ~ B u s i n e s s+C i v i l ~ R i g h t s ~(~} \mathrm{p}<.05\right)$

${ }^{\mathrm{e}}$ Civil Rights vs No Rationale $(\mathrm{p}<.05)$

${ }^{\mathrm{f}}$ Business+Civil Rights is significantly different from No Rationale $(\mathrm{p}<.05)$
} 
Participants who viewed the video with the civil rights law framing were also more likely to recommend the Black job candidate for promotion. Of those who said they would "Probably Promote Darnell," 36 percent of participants in the Civil Rights Law condition recommended this option compared to only 24 percent in the Business Case condition. No participants in any condition selected "Definitely Promote Darnell." I conducted an ordered logistic regression on the resulting three level categorical variable "Definitely Promote John," "Probably Promote John" or "Probably Promote Darnell." The odds of probably promoting Darnell (versus probably or definitely promoting John) are 2.3 times greater for those in the Civil Rights Law condition than those in the Business Case condition $(\mathrm{OR}=2.31, \mathrm{p}=.044)$ (see Table 3$)$.

Table 3. Ordinal Logistic Regression Model to Predict the Promotion of a Black Job Candidate

\begin{tabular}{|l|c|c|c|}
\hline & Odds Ratio & $95 \%$ CI & P-value \\
\hline Civil Rights vs. Business & $2.31 *$ & $.19-.98$ & 0.04 \\
\hline Business + Civil Rights vs. Business & 1.71 & $.34-1.60$ & 0.21 \\
\hline No Rationale vs. Business & 1.57 & $.32-1.45$ & 0.28 \\
\hline
\end{tabular}

Moral Beliefs Mediate Behavior. While commonplace, organizational framing around the business case is less likely to lead to promotion of a Black job candidate than framing about civil rights law, $\mathrm{b}=-0.81, \mathrm{p}=0.05$. Expanding on this finding that the diversity framing has a main effect on promotion decision, I conducted a mediation analysis using generalized structural equation modeling. Based on a well-established literature on the normative influence of law, I hypothesized that moral beliefs about diversity and inclusion mediate the effects of diversity framing on workplace decisions.

Figure 5 shows that moral beliefs are a critical mechanism that make a particular framing effective. More specifically, the effect of diversity framing on the promotion decision is mediated by the belief that striving for diversity is "the right thing to do." Participants exposed to civil rights law were more likely to perceive striving for diversity as a morally important than those exposed to the Business case, $b=-0.93, p=0.01$. When I regressed the promotion 
decision on the belief that diversity is moral and the diversity framing, the moral beliefs have a direct effect on the promotion decision, $b=0.31, p=0.03$. When I add this belief as a control between the promotion decision and the diversity framing, the framing effect loses significance, from $b=-0.81$ to $b=-0.63, p=0.14$. Along the bottom path, the value below the arrow shows the main effect of framing on promotion decision, and the value above the arrow shows the direct effect after I controlled for the mediator. This confirms the hypothesis that moral beliefs about diversity are a critical link between diversity framing and workplace inclusion.

Figure 5. Why Framing Matters: Moral Beliefs about Diversity Mediate Inclusive DecisionMaking

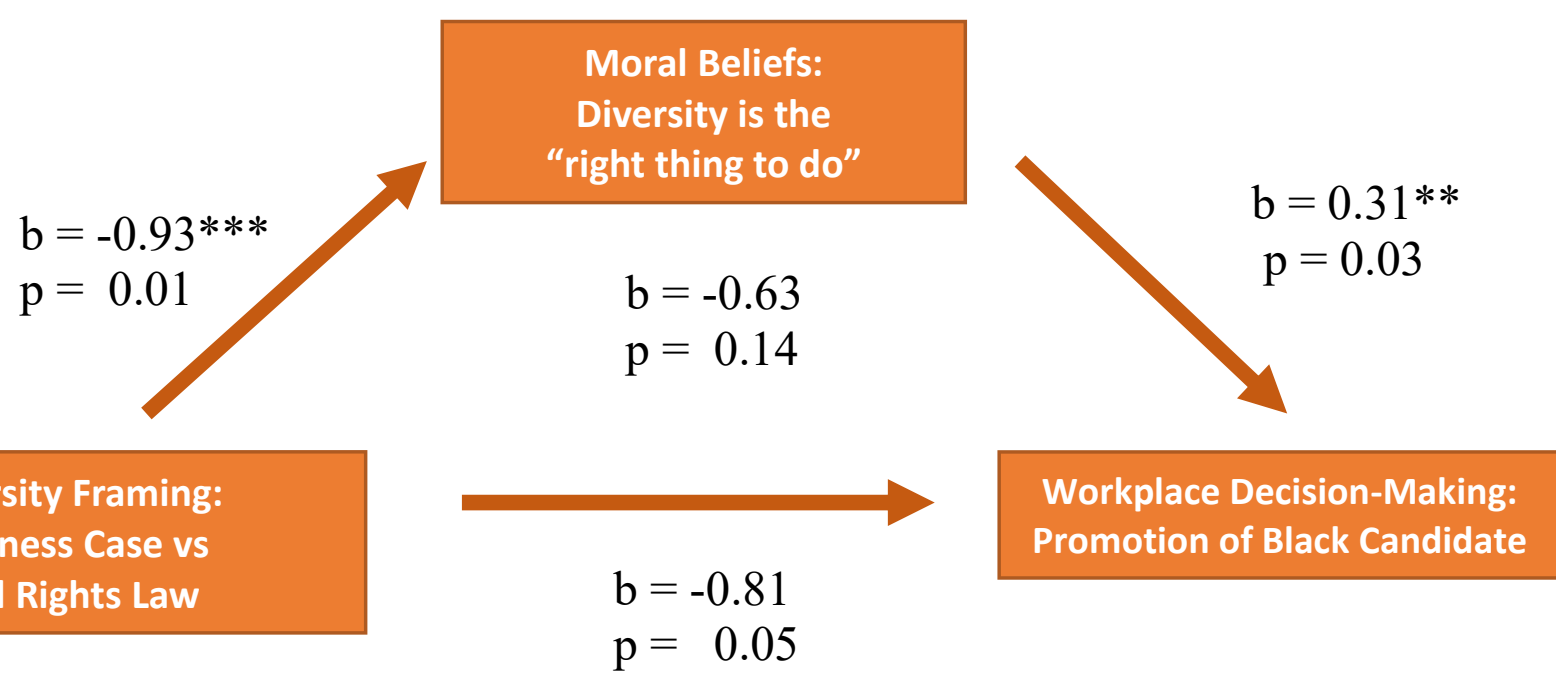

Diversity Framing:

Business Case vs

Civil Rights Law

$$
\mathrm{p}=0.05
$$

Overall, these findings support the proposition that the efficacy of diversity training will vary based on the framing or rationale presented. I found that civil rights law led to more positive effects on beliefs and behavior than the business case. These social psychological insights can help inform debates on both the detrimental effects of legal compliance training and the benefits of the business case. As discussed below, these findings are consistent with sociological literature on the normative influence of law.

\section{DISCUSSION}

These findings make three primary contributions. First, they reveal that all diversity trainings are not created equally, and that the framing can shape how training influences beliefs 
and behaviors. Despite the perceived rationality of profit- and performance-based rationales endorsed by Corporate America, findings from Experiment 1 and Experiment 2 suggest that training focused on a business case for diversity may be counterproductive, leading to increased inequality.

In addition, the findings clarify that the moral belief that striving for diversity is "the right thing to do" is a critical social psychological mechanism that could help create more positive outcomes in organizational diversity training. More specifically, exposure to civil rights law promotes positive beliefs about inclusion, such as consciousness of institutional discrimination and reduced color-blind denial, while also increasing the belief that inclusion is "the right thing to do" (Bobo and Hutchings 1996; Janssens et al. 2010; Albiston et al. 2012). This in turn promotes more positive outcomes relative to a business case that is more instrumental, focused on what can be gained from diversity.

This finding is consistent with research on the normative influence of law which suggests that law has a meaningful impact separate from the threat of penalties it imposes. Participants faced no personal penalties in the legal condition. Rather than primarily evaluating choices according to costs and benefits, they seemed to be engaging in normative decision making according to moral values. Exposing an individual to civil rights law, then, may help engender moral values that could make that individual more attuned to potential bias and reduce discriminatory behaviors. In the long run, re-framing organizational training and other messaging about diversity to similarly inspire moral beliefs about diversity and inclusion could potentially help reduce systemic bias within organizations (Berkowitz and Walker 1967; Suchman 1997).

Advancing our understanding of the mechanisms involved in inclusion processes may help explain why racial inequality persists in many organizations despite strategic diversity interventions such as diversity training. Future research should also specifically explore the effectiveness of moral framing that is not tied to law. Although this study did not examine an explicit moral case for diversity as a separate condition, results suggest that this may be an effective approach. A morality and fairness rationale is founded upon the tenet that diversity efforts are important because inclusion is the right thing to do. While organizational leaders often frame diversity around a business case that emphasizes profit, the core American values of 
equity, fairness, and morality may be more effective in the long run and less likely. This line of research and theory development will continue to aid our understanding of organizational inequality and further clarify the conditions under which diversity, inclusion, and equity interventions have positive or negative effects on addressing that inequality.

\section{ENDNOTES}

1. Research has demonstrated that, in regard to widely held beliefs about race and gender, students typically exhibit the same behavior as those outside the university. For example, in a study about bias against working mothers, Correll, Benard, and Paik (2007) followed their laboratory study with a wide-scale audit study that confirmed real employers were biased against mothers to the same degree undergraduate students were. Research has also established that there is no difference in contemporary measures of racism between Whites in student samples and those in the general population (Henry and Sears 2005).

2. Not selecting Black teammate $=$ participant selects self despite inferior performance, or participant selects White teammate.

3. Since, as described below, participants were asked to make a promotion decision, the ideal sample would be a nationally representative sample of managers. However, it is encouraging that this sample includes a high concentration of managers. 


\section{REFERENCES}

Albiston, Catherine R., Shelley J. Correll, Christina Stevens, and Traci Tucker. 2012. "Law, Norms, and the Motherhood/Caretaker Penalty." $7^{\text {th }}$ Annual Conference on Empirical Legal Studies Paper. Retrieved June 24, 2016 (http://ssrn.com/abstract=2109919).

Albiston, Catherine R., and Lindsey T. O'Connor. 2016. “Just Leave.” Harv. Women's Law Journal 39: 1-66.

Bartlett, Katharine T. 2009. "Making Good on Good Intentions: The Critical Role of Motivation in Reducing Implicit Workplace Discrimination.” Virginia Law Review 95(8):1893-1972.

Berkowitz, Leonard, and Nigel Walker. 1967. "Laws and Moral Judgments." Sociometry 30(4):410-22.

Bobo, Lawrence, and Vincent L. Hutchings. 1996. "Perceptions of Racial Group Competition: Extending Blumer's Theory of Group Position to a Multiracial Social Context." American Sociological Review 61(6):951-72.

Bobo, Lawrence, James R. Kluegel, and Ryan A. Smith. 1997. "Laissez-faire Racism: The Crystallization of a Kinder, Gentler, Antiblack Ideology.” Pp. 15-42 in Racial Attitudes in the 1990s: Continuity and Change, edited by S. A. Tuch, and J. K. Martin. Westport, CT: Praeger.

Bond, Meg A., and Michelle C. Haynes. 2014. "Workplace diversity: A Social-Ecological Framework and Policy Implications." Social Issues and Policy Review 8.1: 167-201.

Bonilla-Silva, Eduardo. 2021. Racism without Racists: Color-Blind Racism and the Persistence of Racial Inequality. 6th ed. Lanham, MD: Rowman and Littlefield Publishers.

Camerer, Colin F., and George Loewenstein. 2011. Advances in Behavioral Economics. Princeton, NJ: Princeton University Press.

Correll, Shelley J., Stephen Benard, and In Paik. 2007. "Getting a Job: Is There a Motherhood Penalty?" American Journal of Sociology 112(5):1297-1338.

Dobbin, Frank R., and Alexandra Kalev. 2016. "Why Diversity Programs Fail: And What Works Better." Harvard Business Review, Summer 2016.

Dobbin, Frank. 2009. Inventing Equal Opportunity. Princeton, NJ: Princeton University Press. 
Dover, Tessa L., Brenda Major, and Cheryl R. Kaiser. 2016. "Members of High-status Groups Are Threatened by Pro-diversity Organizational Messages." Journal of Experimental Social Psychology 62:58-67.

Edelman, Lauren B. and Jessica Cabrera. 2020. "Sex-Based Harassment and Symbolic Compliance." Annual Review of Law and Social Science 16:361-383.

Edelman, Lauren B., Sally Riggs Fuller, and Iona Mara-Drita. 2001. "Diversity Rhetoric and the Managerialization of Law.” American Journal of Sociology 106(6):1589-1641.

Ely, Robin J., and David A. Thomas. 2001. "Cultural Diversity at Work: The Effects of Diversity Perspectives on Work Group Processes and Outcomes.” Administrative Science Quarterly 46(2):229-73.

Embrick, David G. "The Diversity Ideology in the Business World: A New Oppression for a New Age.” 2011. Critical Sociology 37.5:541-556.

Esen, Evren. 2005. 2005 Workplace Diversity Practices: Survey Report. Alexandria, VA: Society for Human Resource Management. Retrieved June 28, 2016 (https://www.shrm.org/Research/SurveyFindings/Articles/Documents/050509WkplcDivPrcSR_FINAL_rev.pdf).

Goffman, Erving. 1974. Frame Analysis: An Essay on the Organization ofEexperience. Cambridge, MA: Harvard University Press.

Green, Tristin K. 2003. "Discrimination in Workplace Dynamics: Toward a Structural Account of Disparate Treatment Theory." Harvard Civil Rights-Civil Liberties Law Review 38(1):91-157.

Gratz v. Bollinger, 539 U.S. 244 (2003).

Hansen, Fay. 2003. “Diversity’s Business Case: Doesn't Add Up.” Workforce, April 2003, pp. 28-32.

Henry, P. J., and David O. Sears. 2005. “The Symbolic Racism 2000 Scale.” Political Psychology 23(2):253-83.

Herring, Cedric. 2009. "Does Diversity Pay?: Race, Gender, and the Business Case for Diversity." American Sociological Review 74(2):208-24. 
Holladay, Courtney L., Jennifer L. Knight, Danielle L. Paige, and Miguel A. Quiñones. 2003. "The Influence of Framing on Attitudes toward Diversity Training." Human Resource Development Quarterly 14(3):245-63.

Janssens, Maddy, Myriam Bechtoldt, Arie de Ruijter, Dino Pinelli, Giovanni Prarolo, and Vanja

M. K. Stenius, eds. 2010. The Sustainability of Cultural Diversity: Nations, Cities and

Organizations. Cheltenham, UK: Edward Elgar Publishing.

Jayne, Michele E. A., and Robert L. Dipboye. 2004. "Leveraging Diversity to Improve Business Performance: Research Findings and Recommendations for Organizations." Human Resource Management 43(4):409-24.

Jones, Kristen P., Chad I. Peddie, Veronica L. Gilrane, Eden B. King, and Alexis L. Gray. 2013. "Not So Subtle: A Meta-Analytic Investigation of the Correlates of Subtle and Overt Discrimination." Journal of Management, first published on October 11, 2013 as doi:10.1177/0149206313506466.

Kaiser, Cheryl R., Brenda Major, Ines Jurcevic, Tessa L. Dover, Laura M. Brady, and Jenessa R. Shapiro. 2013. "Presumed Fair: Ironic Effects of Organizational Diversity Structures." Journal of Personality and Social Psychology 104(3):504-19.

Kalev, Alexandra and Frank Dobbin. 2016. "Try and Make Me! Why Corporate Diversity Training Fails." Presented at the Institute for Work and Employment Research, Cambridge, MA.

Kalev, Alexandra, Frank Dobbin, and Erin Kelly. 2006. "Best Practices or Best Guesses? Assessing the Efficacy of Corporate Affirmative Action and Diversity Policies." American Sociological Review 71(4):589-617.

Kidder, Deborah L., Melenie J. Lankau, Donna Chrobot-Mason, Kelly A. Mollica, and Raymond Friedman. 2004. "Backlash toward Diversity Initiatives: Examining the Impact of Diversity Program Justification, Personal and Group Outcomes.” International Journal of Conflict Management 15(1):77-102.

Krieger, Linda Hamilton. 2000. “Socio-Legal Backlash.” Berkeley Journal of Employment and Labor Law 21(1):476-520. 
Lawler, E. J., Ridgeway, C., \& Markovsky, B. 1993. "Structural Social Psychology and the Micro-macro Problem. Sociological Theory, 268-290.

Levitt, Steven D., \& Stephen J. Dubner. 2005. Freakonomics: A Rogue Economist Explores the Hidden Side of Everything. New York: William Morrow \& Co.

Loyd, Denise L., Cynthia S. Wang, Katherine W. Phillips, \& Robert B. Lount Jr,. 2013. "Social Category Diversity Promotes Premeeting Elaboration: The Role of Relationship Focus." Organization Science 24(3):757-772

Lucas, Jeffrey W. 2003. "Status Processes and the Institutionalization of Women as Leaders." American Sociological Review 68(3):464-80.

Mannix, Elizabeth, and Margaret A. Neale. 2005. "What Differences Make a Difference? The Promise and Reality of Diverse Teams in Organizations." Psychological Science in the Public Interest 6(2):31-55.

Mayorga-Gallo, Sarah. 2019. "The White-Centering Logic of Diversity Ideology." American Behavioral Scientist 63(13):1789-1809.

Dolan, Kevin, Vivian Hunt, Sara Prince, and Sandra Sancier-Sultan. 2020. "Diversity Still Matters." McKinsey \& Company.

De Meuse, Kenneth P., and Todd J. Hostager. 2001. "Developing an Instrument for Measuring Attitudes toward and Perceptions of Workplace Diversity: An Initial Report." Human Resource Development Quarterly 12.1: 33-51.

Mor Barak, Michal E., David A. Cherin, and Sherry Berkman. "Organizational and Personal Dimensions in Diversity Climate: Ethnic and Gender differences in Employee Perceptions." 1998. The Journal of Applied Behavioral Science 34.1: 82-104.

Neville, Helen A., Germine H. Awad, James E. Brooks, Michelle P. Flores, and Jaime Bluemel. 2013. "Color-Blind Racial Ideology: Theory, Training, and Measurement Implications in Psychology.” American Psychologist 68(6):455-66.

Neville, Helen A., Roderick L. Lilly, Georgia Duran, Richard M. Lee, and LaVonne Browne. 2000. "Construction and Initial Validation of the Color-Blind Racial Attitudes Scale (CoBRAS)." Journal of Counseling Psychology 47(1):59-70. 
Page, Scott E. 2007. The Difference: How the Power of Diversity Creates Better Groups, Firms, Schools, and Societies. Princeton: Princeton University Press.

Phillips, Katherine W., Katie A. Liljenquist, and Margaret A. Neale. 2009. "Is the Pain Worth the Gain? The Advantages and Liabilities of Agreeing with Socially Distinct Newcomers." Personality and Social Psychology Bulletin 35(3):336-50.

Phillips, Katherine W. 2014. "How Diversity Makes Us Smarter.” Scientific American 311(4).

Phillips, Katherine W., Gregory B. Northcraft, and Margaret A. Neale. 2006. "Surface-level diversity and decision-making in groups: When Does Deep-level Similarity Help?" Group Processes \& Intergroup Relations 9(4): 467-482.

Plant, E. Ashby, and Patricia G. Devine. 2001. "Responses to Other-Imposed Pro-Black Pressure: Acceptance or Backlash?” Journal of Experimental Social Psychology 37(6):486-501.

Reskin, Barbara F. 2003. "Including Mechanisms in our Models of Ascriptive Inequality." American Sociological Review 68(1):1-21.

Robinson, Gail, and Kathleen Dechant. 1997. "Building a Business Case for Diversity." Academy of Management Executive 11(3):21-31.

Sears, David O., and P. J. Henry. 2005. "Over Thirty Years Later: A Contemporary Look at Symbolic Racism.” Pp. 95-150 in Advances in Experimental Social Psychology. Vol. 37, edited by M. Zanna. San Diego: Elsevier Academic Press.

Snow, David A., E. Burke Rochford Jr, Steven K. Worden, and Robert D. Benford. 1986. "Frame Alignment Processes, Micromobilization, and Movement Participation." American sociological review 52(4): 464-481.

Norton, Michael I., and Samuel R. Sommers. 2011. "Whites See Racism as a Zero-Sum Game that They Are Now Losing." Perspectives on Psychological science 6(3): 215-218.

Steele, Logan M., and Joseph A. Vandello. 2019. "When Training Backfires and What Can Be Done About It." Industrial and Organizational Psychology 12(1): 30-33.

Sturm, Susan. 2001. "Second Generation Employment Discrimination: A Structural Approach." Columbia Law Review 101(3):458-568. 
Suchman, Mark C. 1997. “On Beyond Interest: Rational, Normative and Cognitive Perspectives in the Social Scientific Study of Law." Wisconsin Law Review 1997(3):475-501.

Thomas, Kecia M., and Victoria C. Plaut. 2008. "The Many Faces of Diversity Resistance in the Workplace.” Pp. 1-22 in Diversity Resistance in Organizations, edited by K. M. Thomas. New York: Lawrence Erlbaum Associates.

Tinkler, Justine Eatenson, Yan E. Li, and Stefanie Mollborn. 2007. "Can Legal Interventions Change Beliefs? The Effect of Exposure to Sexual Harassment Policy on Men's Gender Beliefs." Social Psychology Quarterly 70(4):480-94.

Van Knippenberg, Daan, and Michaéla C. Schippers. 2007. "Work Group Diversity.” Annual Review of Psychology 58:515-41.

Williams, Jamillah, and Jonathan Cox. 2020. "The New Principle-Practice Gap: The Disconnect between Diversity Beliefs and Actions in the Workplace." In American Sociological Association Annual Meeting.

Zelditch, Morris, Jr. 1969. “Can You Really Study an Army in the Laboratory?” Pp. 528-39 in A Sociological Reader on Complex Organizations, edited by A. Etzioni. $2^{\text {nd }}$ ed. New York: Holt, Rinehart and Winston. 


\section{APPENDICES}

Appendix A. Experiment 1 Racial Attitudes: Symbolic Racism 2000 Scale

1. It's really a matter of some people not trying hard enough; if blacks would only try harder they could be just as well off as whites.

$<1>$ Strongly agree

$<2>$ Somewhat agree

$<3>$ Somewhat disagree

$<4>$ Strongly disagree

2. Irish, Italian, Jewish and many other minorities overcame prejudice and worked their way up. Blacks should do the same.

$<1>$ Strongly agree

$<2>$ Somewhat agree

$<3>$ Somewhat disagree

$<4>$ Strongly disagree

3. Some say that black leaders have been trying to push too fast. Others feel that they haven't pushed fast enough. What do you think?

$<1>$ Trying to push very much too fast

$<2>$ Going too slowly

$<3>$ Moving at about the right speed

4. How much of the racial tension that exists in the United States today do you think blacks are responsible for creating?

$$
\begin{aligned}
& <1>\text { All of it } \\
& <2>\text { Most } \\
& <3>\text { Some } \\
& <4>\text { Not much at all }
\end{aligned}
$$


5. How much discrimination against blacks do you feel there is in the United States today, limiting their chances to get ahead?

$$
\begin{aligned}
& <1>\text { A lot } \\
& <2>\text { Some } \\
& <3>\text { Just a little } \\
& <4>\text { None at all }
\end{aligned}
$$

6. Generations of slavery and discrimination have created conditions that make it difficult for blacks to work their way out of the lower class.

$$
\begin{aligned}
& <1>\text { Strongly agree } \\
& <2>\text { Somewhat agree } \\
& <3>\text { Somewhat disagree } \\
& <4>\text { Strongly disagree }
\end{aligned}
$$

7. Over the past few years, blacks have gotten less than they deserve.

$$
\begin{aligned}
& <1>\text { Strongly agree } \\
& <2>\text { Somewhat agree } \\
& <3>\text { Somewhat disagree } \\
& <4>\text { Strongly disagree }
\end{aligned}
$$

8. Over the past few years, blacks have gotten more economically than they deserve.

$$
\begin{aligned}
& <1>\text { Strongly agree } \\
& <2>\text { Somewhat agree } \\
& <3>\text { Somewhat disagree } \\
& <4>\text { Strongly disagree }
\end{aligned}
$$

Note: The following is the standard procedure for combining the items into a scale: After collecting the data, items 1, 2, 4, and 8 need to be recoded so that a $1=4,2=3,3=2$, and 4 
$=1$. Item 3 needs to be recoded so that $1=3,2=1$, and $3=2$. For combining the items into a scale, there are several options, ranging from the simplest to the most precise: (1) One could simply add the raw scores together for each item, so that each individual has a score that could range from 8 to 31; (2) To compensate for any missing data, one could average the raw scores; or (3) To compensate for the differences in the number of response alternatives, one could recode each of the items on a 0 to 1 scale, so for item \#3, a $1=1,2=0$, and $3=.50$, and for the other items the high response is a 1 , the next a .66 , the next a .33 , and the low response is a 0 . (This third technique is the one used in Henry \& Sears (2002).) (4) To equate the variability across items, one could create standardized $(\mathrm{z})$ scores for each of the items in the scale, then average the responses. 


\section{Appendix B. Experiment 2 Promotion Decision Scenario}

Dear Member of Max Corp. Committee,

Please carefully review the case and be prepared to share your recommendations with the committee.

Darnell is a fourth year associate at Max Corp. When John, a new associate with previous experience was hired, a senior partner asked Darnell to "show him the ropes" at Max Corp.

Darnell, John, and the senior partner would all be working together in the same division. Darnell agreed and felt that this would be a good opportunity to demonstrate his leadership at the company. After a few months, Darnell noticed that John and the partner were getting along very well. The partner praised John's performance, they frequently went out to lunch, and they were always chatting amongst themselves in the partner's office. Darnell also noticed that John was receiving more of the assignments with the most prestigious clients.

A year later, John was recommended for promotion, mainly as a result of his performance on a case with a very prestigious client and a fine recommendation from the partner. Although both employees did promising work and had similar evaluations on record, Darnell was not recommended for promotion. Darnell became concerned due to the fact that, of 39 associates who were promoted this year at Max Corp, only three were members of a racial minority group.

Darnell has requested that his situation be reviewed. 
Appendix C. Experiment 2 Racial Attitudes: Colorblind Racial Attitudes Scale

(CoBRAS)

CoBRAS Items, Factor Loadings, and Means and Standard Deviations for Study I

\begin{tabular}{|c|c|c|c|c|c|c|}
\hline \multirow{2}{*}{\multicolumn{2}{|c|}{ Item }} & \multicolumn{3}{|c|}{ Factor loadings } & \multirow[b]{2}{*}{$M$} & \multirow[b]{2}{*}{$S D$} \\
\hline & & Factor 1 & Factor 2 & Factor 3 & & \\
\hline (16.) & $\begin{array}{l}\text { White people in the U.S. have certain } \\
\text { advantages because of the color of their } \\
\text { skin. }\end{array}$ & .68 & .21 & .31 & 2.85 & 1.52 \\
\hline (10.) & $\begin{array}{l}\text { Race is very important in determining } \\
\text { who is successful and who is not. }\end{array}$ & .66 & .22 & .16 & 4.43 & 1.53 \\
\hline (26.) & $\begin{array}{l}\text { Race plays an important role in who gets } \\
\text { sent to prison. }\end{array}$ & .64 & .16 & .27 & 3.91 & 1.65 \\
\hline (04.) & $\begin{array}{l}\text { Race plays a major role in the type of } \\
\text { social services (such as type of health care } \\
\text { or day care) that people receive in the } \\
\text { U.S. }\end{array}$ & .62 & .04 & .03 & 3.54 & 1.42 \\
\hline (12.) & $\begin{array}{l}\text { Racial and ethnic minorities do not have } \\
\text { the same opportunities as white people in } \\
\text { the U.S. }\end{array}$ & & & & & \\
\hline 01. & $\begin{array}{l}\text { the U.S. } \\
\text { Everyone who works hard, no matter what } \\
\text { race they are, has an equal chance to }\end{array}$ & .62 & .31 & .24 & 3.49 & 1.56 \\
\hline (19.) & $\begin{array}{l}\text { become rich. } \\
\text { White people are more to blame for racial }\end{array}$ & .58 & .29 & .18 & 3.92 & 1.75 \\
\hline & $\begin{array}{l}\text { discrimination than racial and ethnic } \\
\text { minorities. }\end{array}$ & .54 & .39 & .15 & 3.90 & 1.55 \\
\hline 20. & $\begin{array}{l}\text { Social policies, such as affirmative action, } \\
\text { discriminate unfauirly against white people. } \\
\text { White peonie in the US are discrimimated }\end{array}$ & .27 & .77 & .14 & 3.32 & 1.60 \\
\hline & $\begin{array}{l}\text { White people in the U.S. are discriminated } \\
\text { against because of the color of their skin. }\end{array}$ & .09 & .67 & -.11 & 2.78 & 1.55 \\
\hline (07) & $\begin{array}{l}\text { English should be the only official lan- } \\
\text { guage in the U.S. }\end{array}$ & .18 & .65 & .17 & 3.94 & 1.85 \\
\hline (07.) & $\begin{array}{l}\text { Due to racial discrimination, programs } \\
\text { such as affirmative action are necessary to } \\
\text { help create equality. }\end{array}$ & .31 & .64 & .18 & 3.30 & 1.75 \\
\hline 22. & $\begin{array}{l}\text { Racial and ethic minorities in the U.S. } \\
\text { have certain advantages because of the }\end{array}$ & & & & & \\
\hline 06. & $\begin{array}{l}\text { color of their skin. } \\
\text { It is important that people begin to think } \\
\text { of themselves as American and not }\end{array}$ & .16 & .62 & .09 & 3.37 & 1.43 \\
\hline 17. & $\begin{array}{l}\text { African American, Mexican American or } \\
\text { Italian American. } \\
\text { Immigrants should try to fit into the cul. }\end{array}$ & .07 & .55 & .35 & 3.43 & 1.78 \\
\hline 23. & $\begin{array}{l}\text { ture and values of the U.S. } \\
\text { Racial problems in the U.S. are rare, iso- }\end{array}$ & -.03 & .48 & .38 & 3.71 & 1.48 \\
\hline 14. & $\begin{array}{l}\text { lated situations. } \\
\text { Talking about racial issues causes unnec- }\end{array}$ & .31 & .04 & .65 & 1.93 & 1.23 \\
\hline & essary tension. & -.09 & & 0 & 3.09 & 1. \\
\hline $\begin{array}{l}(09 .) \\
(21 .)\end{array}$ & $\begin{array}{l}\text { Racism is a major problem in the U.S. } \\
\text { It is important for public schools to teach }\end{array}$ & .39 & -.03 & .61 & 2.23 & 13 \\
\hline (15.) & $\begin{array}{l}\text { about the history and contributions of } \\
\text { racial and ethnic minurities. } \\
\text { It is important for political leaders to talk }\end{array}$ & .17 & .13 & .56 & 1.76 & 1.03 \\
\hline & & .23 & .26 & .56 & 2.38 & 1.34 \\
\hline 11. & $\begin{array}{l}\text { Racism may have been a problem in the } \\
\text { past, it is not an important problem today. }\end{array}$ & .24 & .16 & .53 & 2.19 & 1.32 \\
\hline
\end{tabular}

Note. Item numbers in parentheses have been reverse scored. Unique factor loadings $>.40$ are in bold. Analysis is based on 282 observations. CoBRAS items range from $1-6$. Total CoBRAS scores range from 20 to 120 . Factor 1 and Factor 2 scores range from 7 to 42 . Factor 3 scores range from 6 to 36. CoBRAS = Color-Blind Racial Attitudes Scale. 